\title{
Noncognitivism in Metaethics and the Philosophy of Action
}

\author{
Samuel Asarnow \\ Macalester College \\ sasarnow@macalester.edu \\ Forthcoming in Erkenntnis
}

\begin{abstract}
Noncognitivism about normative judgment is the view that normative judgment is a distinctive kind of mental state, identical neither to belief or desire, but desire-like in its functional role and direction of fit. Noncognitivism about intention (also called the "distinctive practical attitude" theory) is the view that intention is a distinctive kind of mental state, identical neither to belief or desire, but desire-like in its functional role and direction of fit. While these theories are alike in several ways, they have rarely been discussed in concert. This paper studies the relation between these two theories, focusing on the question of whether noncognitivism about intention faces an analogue of the well-known Frege-Geach problem for noncognitivism about normative judgment. I argue that whether it faces the Frege-Geach problem depends on how it treats the distinction between what Anscombe called expressions of intention and personal predictions. I show that there is substantial pressure to treat that distinction as semantic, and that a variant of the Frege-Geach problem arises for versions of noncognitivism about intention that go this route. Yet some philosophers of action may be willing to resist this pressure, and I develop a pragmatic account of the distinction that would allow such philosophers to avoid the Frege-Geach problem altogether. I argue that this pragmatic account has significant independent appeal. Notably, it provides a way for noncognitivists about intention to undercut the force of a recent argument for cognitivism due to Berislav Marušić and John Schwenkler.
\end{abstract}

\section{Introduction}

According to a broadly Humean approach to psychology and action, a complete understanding of human motivation and action can be given by positing exactly two types of mental states, beliefs and desires, which are (as Hume might have said) distinct existences. Some philosophers challenge the mutual exclusivity of this distinction, positing "besires" that 
simultaneously count as both belief and desire. Others dispute the distinction's exhaustiveness, positing the existence of additional mental state types. ${ }^{1}$

Two influential positions in metaethics and the philosophy of action fall in the latter camp. Noncognitivists about normative judgment argue that a plausible account of normative thought (and, by extension, normative language) requires enriching the Humean picture. They claim normative judgment is a distinctive kind of mental state, identical neither to belief or desire. ${ }^{2}$ While it is desire-like in its functional role and direction of fit, it also has belief-like characteristics, such as being subject to requirements of rationality. ${ }^{3}$ Noncognitivism about normative judgment (NNJ) contrasts with cognitivism, the idea that normative thoughts are beliefs.

Analogously, noncognitivists about intention argue that intention is a distinctive kind of mental state, identical neither to belief or desire, but possessing both desire-like and belief-like characteristics. ${ }^{4}$ Noncognitivism about intention (NI) contrasts with a variety of other views about intention and intentional action, including the cognitivist view that intention is a kind of belief.

Each of these noncognitivisms enriches the traditional belief-desire account of human psychology and action in similar ways. It thus is natural to see them as fellow travelers, and some philosophers (perhaps many) who accept each one also accept the other. Allan Gibbard and Mark Schroeder have influentially suggested that the independent plausibility of NI provides a "license

\footnotetext{
${ }^{1}$ For a defense of both mutual exclusivity and exhaustiveness, see (Sinhababu 2017).

${ }^{2}$ Strictly speaking, the broadly Hobbesian view that normative judgments are desires is a form of noncognitivism. But even early contemporary discussions of NNJ deny the Hobbesian view; c.f., e.g., (Stevenson 1937, 16).

${ }^{3}$ See, e.g., (Blackburn 1993, 1998; Gibbard 2003, 1990a, 2012, 284ff). Noncognitivists about normative judgment do not challenge the mutual exclusivity of belief and desire (usually called the "Humean theory of motivation," as in (Smith 1994, chap. 4)).

${ }^{4}$ On noncognitivism about intention, see (M. E. Bratman 1987; Mele 1992; Paul 2009; M. E. Bratman 1999). Sarah Paul calls it the "distinctive practical attitude" theory.
} 
for optimism" (as Schroeder has put it) about the prospects for NNJ. ${ }^{5}$ Strikingly, aside from those important discussions, the two views have not often been discussed in concert.

The goal of this paper is to study the relation between these two philosophical projects. I focus on an influential objection to NNJ, the Frege-Geach problem, which challenges NNJ to flesh out the expressivist semantics with which it is ordinarily paired. My question will be whether an analogue of this problems arises for NI.

I argue that whether the Frege-Geach problem arises for NI depends on underexplored issues in the philosophy of language, concerning how NI treats the distinction between what have been called "expressions of intention" and first-personal predictions of behavior. I argue that philosophers sympathetic to Elizabeth Anscombe's well-known characterization of that distinction face pressure to treat the distinction as semantic. This likely leads them to a kind of expressivism about expressions of intention, and, in turn, to a version of the Frege-Geach problem. I also show, however, that those willing to part ways with Anscombe can instead treat the distinction as pragmatic, in a way I describe, and thus avoid the Frege-Geach problem. I develop one possible pragmatic account of this distinction, and argue that it has several other virtues, one of which is that it would undercut the force of a recent argument for cognitivism about intention, due to Berislav Marušić and John Schwenkler. ${ }^{6}$

The overall discussion of the paper suggests two broader morals for metaethics and the philosophy of action. The first is that it is far from clear whether the plausibility of NI provides a "license for optimism" for NNJ. NNJ may be the correct theory of normative thought, but NI's plausibility has does not lend it substantial credence. Second, philosophers of action interested in

\footnotetext{
${ }^{5}$ See (Gibbard 2003, chaps. 1-3). Compare also (Schroeder 2008, 42ff), as well as (Baker and Woods 2015; Beddor 2020).

${ }^{6}$ (Marušić and Schwenkler 2018).
} 
intention would do well to pay more attention to issues of language than they sometimes have; my discussion of the pragmatics of expressions of intention is only the beginning of an account of the language we use to express intentions. A theory of mind and action without a theory of intention, a theory of normative judgment, and a theory of the language used to express those states of mind, is incomplete.

The paper proceeds as follows. Section 1 introduces the two noncognitivisms. Section 2 describes the Frege-Geach problem in the context of NNJ. Sections 3 and 4 study whether that problem arises for NI and argue for the specific conclusions discussed above.

\section{Two Noncognitivisms}

According to NI, intention is a distinctive type of mental state, identical neither to belief nor desire. Intention is desire-like in its direction of fit and functional role, in that it motivates action rather than representing the world. But intention is belief-like in its susceptibility to requirements of rationality and its role in reasoning: unlike desires, intentions can be both inputs to and outputs of reasoning, and agents with inconsistent intentions (but not inconsistent desires) are thereby criticizably irrational. ${ }^{7}$ The most prominent version of NI is Michael Bratman's "planning theory" of intention. ${ }^{8}$ I call this view "noncognitivism" to highlight its contrast with cognitivism, the view that intention is a type of belief. ${ }^{9}$ Other alternatives include the idea that

\footnotetext{
${ }^{7}$ That desires are not subject to requirements of rationality is a widespread assumption in this dialectic. For defenses of that idea, see, e.g., (M. E. Bratman 1987, chap. 1; Baker 2010), as well as (Shah and Velleman 2005; Velleman 2000; Broome 2013, chap. 6). For defenses of this assumption in metaethical contexts, see (Stevenson 1937; Schroeder 2009, chap. 7). For the contrary view, see (Smith 1994).

${ }^{8}$ (M. E. Bratman 1987).

${ }^{9}$ See, e.g., (Harman 1976; Velleman 1989; Setiya 2007a, 2007b; Chislenko 2016; Marušić and Schwenkler 2018).
} 
intentions reduce to a complex of beliefs and desires,${ }^{10}$ that intending to act is a form of acting, ${ }^{11}$ and that intention is the combination of a noncognitive attitude with belief. ${ }^{12}$

NNJ (in its most prominent contemporary form) centers on a pair of commitments. ${ }^{13}$ First, NNJ holds that normative judgment consists in a distinctive kind of mental state, rather than belief. For example, some proponents of NNJ hold that a person's thought that eating meat is wrong consists in a state of disapproving of eating meat, or planning not to eat meat, or being for blaming for eating meat. ${ }^{14}$ However the type of mental state is understood, it is said to be desire-like in its direction of fit and functional role, but belief-like in its susceptibility to requirements of rationality and its role in reasoning, in the way described above. ${ }^{15}$ Normative judgments can be inputs and outputs of reasoning, and agents with inconsistent judgments are irrational.

Second, NNJ adopts expressivism about normative sentences such as (a):

(a) Eating meat is wrong.

Expressivists hold that the meaning of (a) is (a function of) the mental state it expresses. ${ }^{16}$ Expressivism solves an important problem facing the alternative speaker-subjectivist semantics that might be associated with NNJ. ${ }^{17}$ According to speaker subjectivism, the meaning of (a) is its

\footnotetext{
${ }^{10}$ See, e.g., (Audi 1973; Davis 1984; Ridge 1998; Sinhababu 2013).

11 (Thompson 2008).

12 (Grice 1971).

${ }^{13}$ This is, roughly, the "quasi-realism" of Blackburn and Gibbard. See (Blackburn 1993, 1998; Gibbard 2003, 1990a, 2012, 284ff).

${ }^{14}$ As in (Blackburn 1993; Gibbard 2003; Schroeder 2008), respectively.

${ }^{15}$ While quasi-realists hold that normative judgments are beliefs in a deflationary sense, plausibly, they must hold that normative judgments have a different functional role than descriptive beliefs. Compare (Gibbard 2003, chap. 3; Dreier 2004; Schroeder 2008, chap. 7).

16 See (Gibbard 2012, 284ff) and (Schroeder 2008). Whether expressivism is best understood as a semantic or metasemantic theory is controversial; see, e.g., (Woods 2017).

${ }^{17}$ For an overview, see (Schroeder 2009, chap. 4)
} 
truth conditions, but its truth conditions are that the speaker is in a certain noncognitive state. Speaker subjectivism, unlike expressivism, implausibly fails to predict the inconsistency of certain inconsistent sets of sentences (such as an assertion of (a) by A and an assertion of the negation of (a) by B).

Despite the similarities between NI and NNJ, they have not often been discussed in concert. One influential exception is Gibbard's suggestion that the substantial appeal of NI lends plausibility to NNJ. ${ }^{18}$ Indeed, Gibbard's version of NNJ models the noncognitive mental state to which it appeals on a kind of plan-state in the spirit of NI. Yet Gibbard and subsequent discussions do not consider in depth the relationship between the two views. ${ }^{19}$ Gibbard treats the plausibility of NI as obvious, and argues only that it provides (what Mark Schroeder calls) a "license for optimism" about the prospects for developing NNJ. ${ }^{20}$

The project of this paper is to make some progress toward discussing the relationship between these two theories. My focus will be on a well-known problem facing NNJ, the FregeGeach problem. While some hold that this problem is solvable (or even that it has been solved), many philosophers alive to the concerns that motivate NNJ nonetheless reject it because they believe it cannot be solved. ${ }^{21}$ It thus seems worth investigating the question of whether analogues of these problems also arise for NI.

\footnotetext{
${ }^{18}$ See (Gibbard 2003)

${ }^{19}$ Compare also (Schroeder 2008, 101-3; Beddor 2020).

${ }^{20}$ (Schroeder 2008, 10-12).

${ }^{21}$ Or, that solving it requires paying too steep a theoretical price; see, e.g., (Schroeder 2008).
} 


\section{The Frege-Geach problem for NNJ}

The Frege-Geach problem is a challenge for NNJ's expressivism. ${ }^{22}$ According to expressivism, the meaning of a sentence containing a normative predicate is (a function of) the mental state it expresses; the meaning of (a) is the mental state of (e.g.) disapproval of eating meat. The Frege-Geach problem is the problem of extending this idea to provide a semantic theory for every relevant construction in natural language. ${ }^{23}$

This problem is difficult because it is unclear how expressivism can be so extended. Following Geach, the problem is typically illustrated with sentences in which a normative clause appears in an unasserted context:

(b) If eating meat is wrong, then serving meat to others is wrong.

NNJ holds that the meaning of (b) is (a function of) the mental state it expresses. But it's far from clear what mental state that might be. Nor is it clear how the properties of such a mental state might allow us to recover the semantic properties of (b), such as the fact that (b) and (a) jointly entail (c): $:^{24}$

(c) Serving meat to others is wrong.

Given that normative predicates can appear in any kind of construction that analogous nonnormative predicates can appear in, there is substantial work for expressivism to do. Proponents

\footnotetext{
${ }^{22}$ For overviews, see, e.g., (Geach 1960, 1965; Gibbard 2003; Schroeder 2009, chaps. 6-7, 2008; Woods 2017).

${ }^{23}$ Here I follow (Woods 2017).

${ }^{24}$ On these points, see (Schroeder 2008; Baker and Woods 2015).
} 
of NNJ have responded to this challenge by developing semantic theories that assign appropriate meanings to sentences such as (b), but whether their accounts are successful is a matter of great controversy. ${ }^{25}$

I take no stand here on whether the Frege-Geach problem can be solved. My question will simply be: is NI on the hook for solving it as well?

\section{The Frege-Geach problem for NI}

Whether NI faces the Frege-Geach problem depends on whether NI gives an expressivist semantics for some fragment of natural language. While few if any proponents of NI have explicitly committed themselves to a semantic theory, I argue that some face pressure to adopt expressivism. This pressure comes from reflection on Anscombe's distinction between what she called "expressions of intention" and what I call personal predictions. After explaining Anscombe's characterization of that distinction, I argue that proponents of NI who accept Anscombe's characterization face pressure to explain the difference semantically, which they, in turn, face pressure to do by adopting expressivism. This expressivism generates a variant of the Frege-Geach problem, which I characterize. I consider the prospects for a pragmatic account of the distinction in the section that follows.

\subsection{Expressions of Intention}

In the opening pages of Intention, Anscombe observes that there is a felt difference between two different kinds of first-personal, future tense sentences containing verbs that can be verbs of

${ }^{25}$ Contrast (Gibbard 1990b, 2003, 2012) with, e.g., (Unwin 2001; Schroeder 2008). 
action. In her example, there seems to be a difference between the sentence "I am going for a walk" and the sentence "I am going to be sick." The former typically seems to be an announcement of the speaker's intention, whereas the latter seems to be (only) a prediction of future behavior. ${ }^{26}$ Following Anscombe, the former uses of such sentences are often called "expressions of intention." ${ }^{27}$ I call the latter uses "personal predictions."

Strikingly, this distinction can be felt even when it is not overtly marked. In contemporary American English, for example, one can express an intention using a progressive construction, or using the modal auxiliaries "will" or "shall." Whether a sentence feels like an expression of intention or personal prediction depends on the context. ${ }^{28}$ Sticking to "will" for simplicity, consider this sentence: I will go to Vancouver tomorrow.

Sentence (d) could be an expression of intention. But if the speaker believes they will be kidnapped tomorrow, (d) could be uttered as a personal prediction. ${ }^{29}$

Can the felt difference between these two types of utterances be characterized more precisely? Anscombe herself admitted that the distinction was "rather mystifying," 30 but her discussion of it suggests three candidate differences. First, one might hold that they differ in truth

\footnotetext{
${ }^{26}$ See (Anscombe 2000, secs. 1-3). Here I set aside Anscombe's distinction between predictions and estimates.

${ }^{27}$ Note that Grice famously used the phrase "expressions of intention" differently, at (Grice 1971, 11-12). This terminology should not lead us to prejudge the question of whether NI should adopt expressivism.

${ }^{28}$ Historically, in Britain (excluding Scotland), "I will" was reserved for expressions of intention, while "I shall" was used for both expressions of intention and personal predictions, as was the progressive. See the entries for "will, v.1" (esp. 11 and 16), and "shall, v." (esp. 8) in ("OED Online" 2018), as well as sections 5.131, 5.151 and 5.250 in (Chicago Manual of Style 2017), and 5.149 of (Chicago Manual of Style 2010). Notably, while Anscombe uses progressive sentences as her examples of expressions of intention, in Intention itself she routinely uses "I shall" to express her own intentions and to make personal predictions (cf. (Anscombe 2000, 90,92)).

${ }^{29}$ Compare (M. E. Bratman 1993, 103-4).

${ }^{30}$ (Anscombe 2000, 7).
} 
conditions. Considering an expression of intention, Anscombe writes: "If I do not do what I said I would, I am not supposed to have made a mistake, or even necessarily to have lied; so it seems that the truth of a statement of intention is not a matter of my doing what I said." 31

The second suggestion is that they differ in what I will call sincerity conditions. Anscombe makes this point in her discussion of lying with expressions of intention:

[I]f I lie, what I say is a lie because of something present, not future. I might even be lying in saying I was going to do something, though I afterwards did it. The answer to this is that a lie is an utterance contrary to one's mind, and one's mind may be either an opinion, or a mind to make something the case. ${ }^{32}$

In an Anscombean spirit, one might suggest that a personal prediction is sincere (that is, not a lie) when it is your "opinion" (when you believe it), whereas an expression of intention is sincere when you "have a mind to make it the case" (you intend it).

A third, related suggestion can also be found in Anscombe. Again considering an expression of intention, Anscombe writes:

[I]f I don't do what I said, what I said was not true (though there might not be a question of my truthfulness in saying it). But $[\ldots]$ this falsehood does not necessarily impugn what I said. In some cases the facts are, so to speak, impugned for not being in accordance with

31 (Anscombe 2000, 4).

32 (Anscombe 2000, 4). 
the words, rather than vice versa. [...] [T] he mistake here is one of performance, not of judgment. $^{33}$

Here Anscombe rejects the initial suggestion that the difference lies in truth conditions, instead suggesting that the difference lies in what I will call correctness conditions. In some sense (which a full account of these matters would have to specify), an expression of intention is correct (not “impugnable") when one intends the action, and its correctness is not threatened by certain failures to act. A personal prediction, presumably, is correct when it comes true. This notion of correctness is admittedly obscure, but it clearly differs from sincerity, since a personal prediction can be correct even if insincere.

A proponent of NI sympathetic to Anscombe's suggestions should thus seek an explanation of why expressions of intention and personal predictions differ in truth conditions, sincerity conditions, or correctness conditions, as well as a more precise characterization of the latter two phenomena.

\subsection{The Semantic Approach}

A natural starting point for those seeking such an explanation with Anscombe's suggestion would be to posit a semantic difference between expressions of intention and personal predictions. In particular, taking her first suggestion seriously, one might hold that (through whatever semantic mechanism) they have different truth conditions.

As Anscombe saw, however, this idea is difficult to defend. Plausible candidates for the truth-conditions of expression of intention are not readily available. Consider first the

\footnotetext{
${ }^{33}$ (Anscombe 2000, 4-5).
} 
straightforward suggestion that the truth conditions of (d), when it is an expression of intention, are that the speaker now intends to go to Vancouver tomorrow. This suggestion implausibly entails that expressions of intention can be true even when the person does not perform the intended action. It also assigns implausible truth-conditions in two other types of cases:

(e) A says "I will eat that cookie."

B says: "I will eat that cookie!"

While A's utterance and B's utterance are inconsistent, this proposal assigns them consistent truthconditions. ${ }^{34}$ Compare also:

(f) A says: "I will eat that cookie"

B says: "You don't intend to eat that cookie."

If A's utterance is an expression of intention, there is tension in this conversation, but the two utterances are clearly not logically inconsistent, as this proposal predicts. ${ }^{35}$

Cases such as (f) pose problems for two other suggestions along these lines. The suggestion that the truth-conditions of (d) are that the speaker now intends to go to Vancouver tomorrow and will go to Vancouver tomorrow has implausible consequences in (f). So does the suggestion that (d)'s truth-conditions are that the speaker will go to Vancouver tomorrow in part by way of their intention to go to Vancouver tomorrow. ${ }^{36}$

\footnotetext{
${ }^{34}$ Compare the failure of speaker-subjectivism for NNJ in Section 2. See also, e.g., (Schroeder 2009, chap. 4).

${ }_{35}^{35}$ Compare (Anscombe 2000, 92).

${ }^{36}$ Compare (Harman 1976).
} 
Since the failure of this proposal is closely analogous to the failure of speaker subjectivism as a semantics for normative sentences, the natural next step for a proponent of NI is to turn to expressivism, as well. While expressivism gives up the idea that expressions of intention and personal predictions differ in truth-conditions, it assigns them different semantic values. It thus promises to offer a satisfying explanation of the sense in which they differ in sincerity and correctness conditions. ${ }^{37}$ Moreover, there is precedent for adopting expressivism about this fragment of discourse, as Gibbard has famously developed an expressivist account of expressions of intention. ${ }^{38}$

I thus think a proponent of NI seeking fidelity to Anscombe's suggestions might well be led to adopt expressivism about expressions of intention. ${ }^{39}$ On this view, the semantic values of personal predictions and expressions of intention are not their truth-conditions, but rather the mental states they express (or functions of those mental states). The two types of sentences express different mental states, and so have different semantic values. The semantic value of a personal prediction is a belief, while the semantic value of an expression of intention is an intention.

Does this kind of expressivism generate the Frege-Geach problem? As emphasized above, the Frege-Geach problem is the problem of extending the central expressivist insight to all relevant constructions in natural language, constructs that embed a clause hose semantic value is a noncognitive state appear in an unasserted context. So the question of whether this kind of expressivism generates a challenging version of the Frege-Geach problem depends (in part) on whether expressions of intention can appear in unasserted contexts.

\footnotetext{
${ }^{37}$ Though a full development of this account would need to provide an explanation of cases such as (f).

38 (Gibbard 2003, chap. 1).

${ }^{39}$ Whether Anscombe would accept this approach is unclear. On related issues, see (Moran and Stone 2009).
} 
I cannot consider here the full range of constructions in which expressions of intention might occur (which would include modal constructions, attitude reports, questions, subjunctives, and so on). What I can do is consider a number of important examples. Focusing only on the logical connectives, I argue that there are plausibly at least two types of unasserted contexts in which expressions of intention straightforwardly can embed, though there is also one kind of construction in which (it seems to me) they cannot. So the Frege-Geach problem does arise, in some form, for this kind of expressivism.

The first unasserted context in which it seems to me straightforward that expressions of intention can embed is in the consequents of indicative conditionals whose antecedents are not expressions of intentions, for example:

(g) If the deal falls through, I will go to Vancouver tomorrow.

I think there is a felt difference between uses of (g) that embed (d) as an expression of intention, and those that embed it as a personal prediction. Compare, for example, a speaker using (g) to communicate their readiness to go to Vancouver, and a speaker using (g) in a context where it is clear the failure of the deal will precipitate a kidnapping. Those two uses seem to differ in their sincerity conditions and correctness conditions, in the senses described above. Someone who utters (g) in a way that embeds an expression of intention would be insincere if they don't now intend to go to Vancouver tomorrow should the deal fall through. And someone who utters it as a personal prediction which they believe to be true would be sincere but incorrect if the deal were to fall through but they were not kidnapped after all. 
The second unasserted context in which I think expressions of intention can embed is in disjunctions. This is easiest to see in the case of disjunctions where both disjuncts are expressions of intention, for example:

(h) I will cancel my flight or I will go to Vancouver tomorrow.

As with (g), I think there is a clear felt difference between cases in which the speaker is communicating their readiness to perform either action, and the case in which they are making a disjunctive prediction. The two uses differ in sincerity and correctness conditions.

It also seems plausible to me that expressions of intention can also embed in disjunctions, where the other disjunct is an indicative clause. Compare (on analogy with $(\mathrm{g})$ ):

(i) The deal will fall through, or I will go to Vancouver tomorrow.

I think sentences such as (i) function roughly in the same way as (logically very similar) sentences such as $(\mathrm{g})$. There is a felt difference between a case in which the second disjunct is an expression of intention and one in which it is a personal prediction, which depends on whether it communicates the speaker's readiness to go to Vancouver (should the situation call for it), or whether it communicates a disjunctive prediction. ${ }^{40}$

By contrast, I suspect that expressions of intention cannot embed in the antecedents of conditionals, which is surprising, given their close relationship with disjunctions. Compare first a conditional whose consequent is also an expression of intention:

\footnotetext{
${ }^{40}$ And, assuming sentences like (g) can be read as material conditionals, (g) and (i) are logically equivalent.
} 
(j) If I will go to Vancouver tomorrow, I will bring my passport.

My grasp on Anscombe's ideas of sincerity and correctness conditions is not entirely stable, so I am not entirely sure in my verdicts about these cases, but I cannot clearly distinguish two different readings of $(j)$, one in which the antecedent is an expression of an intention and one in which it is a personal prediction. While I have a sense of what state of mind one might be in when uttering a sentence such as $(\mathrm{g})$ or $(\mathrm{h})$ that embedded an expression of intention (I will suggest below that they may be a conditional intention and a disjunctive intention), I do not have a sense of what state of mind one might express by uttering (j) in a way that embedded two expressions of intention.

Similarly, consider the antecedents of conditionals whose consequent is a prediction:

(k) If I will go to Vancouver tomorrow, the deal will fall through.

As with (j), I cannot clearly distinguish an interpretation of $(\mathrm{k})$ on which the antecedent expresses an intention from one on which it expresses a prediction.

Whether proponents of an expressivist version of NI should say that expressions of intention can embed in (g)-(i), but not (j) and (k), will depend on how the ideas of sincerity conditions and correctness conditions are ultimately precisified. Ideally, they would develop a test that would allow us to make the distinction sharply, which could be applied not only to these sentences, but to the full range of relevant natural language constructions.

If my intuitive judgments are probative, however, they suggest that an expressivist version of NI faces a version of the Frege-Geach problem, albeit one that is differs significantly from the 
version facing NNJ. At minimum, proponents of expressivist versions of NI must explain what mental states are expressed by (g), (h), and (i) and must show how those mental states have properties that allow them to recover the semantic properties of those sentences. And, ideally, they would have an explanation for why expressions of intention cannot embed in (j) and (k).

There is a natural suggestion for how NI can explain (g) and (h), and perhaps (i): (h) expresses a disjunctive intention, while (g) and perhaps (i) express conditional intentions. But conditional intentions and disjunctive intentions are notoriously undertheorized in the literature on NI. ${ }^{41}$ So further theorizing would be needed. Moreover, a constraint on such theorizing would be that it explain why sentences such as $(\mathrm{g})$ and $(\mathrm{h})$ have their evident semantic properties. For example, such an account must explain why (g) and the deal won't fall through together entail (d).

If my intuitions about sentences $(\mathrm{g})-(\mathrm{k})$ are correct, they highlight an analogy between expressions of intention and imperatives that may be dialectically significant in the context of debates about NI and NNJ. ${ }^{42}$

Like expressions of intentions, it is widely thought that imperatives can embed in ( $\mathrm{g}$ )- and (h)-like contexts, but in the antecedents of conditionals. Both of the following are felicitous:

(g') If the deal falls through, go to Vancouver tomorrow

(h') Cancel your flight, or go to Vancouver tomorrow.

Whereas the following are not:

\footnotetext{
${ }^{41}$ But see (Ferrero 2009; Ludwig 2015; Ferrero 2016).
}

42 This was suggested to me by Jack Woods. 
(j') \# If go to Vancouver tomorrow, bring your passport.

(k') \# If go to Vancouver tomorrow, the deal will fall through.

This is a striking similarity between the embedding behavior of expressions of intention and imperatives.

I raise this point about imperatives because of the role of imperatives in the dialectic concerning NI and NNJ. Two points about this analogy deserve emphasis. The first is simply that there is a long history of viewing intentions as closely related to imperatives. ${ }^{43}$ This linguistic data might be seen as supporting that analogy. Moreover, this similarity might suggest that whatever account is given of the semantics of imperative-embedding sentences such as (g') and (h') might be carried over to solve the version of the Frege-Geach problem that affects NI. ${ }^{44}$

The second point is that this analogy between the embedding behavior of imperatives and expressions of intention calls into question whether NNJ can be supported by (what many think is) the plausibility of NI. Gibbard famously argued that an expressivist semantics for NNJ could be modeled on an expressivist semantics for expressions of intention, and Schroeder has suggested that the evident plausibility of NI thus provides a "license for optimism" for NNJ and its expressivist semantic program. ${ }^{45}$ But, while some early expressivists considered modeling their semantics for normative sentences on the semantics of imperatives, that is now widely regarded as a nonstarter, since the embedding behavior of imperatives is significantly different from that of normative clauses. Further reflection on the embedding behavior of expressions of intention is needed, but if (as these reflections suggest) it turns out that they pattern closely with imperatives,

\footnotetext{
${ }^{43}$ For discussion, see (Castañeda 1975, chap. 4,6).

44 This point is in the spirit of (Charlow 2014)

45 See (Gibbard 2003, chaps. 1-3). Compare also (Schroeder 2008, 42ff), as well as (Baker and Woods 2015)
} 
then NI will not be a good model for NNJ after all, and NI will not provide a "license for optimism" about the prospects for NNJ.

One objection to this line of thought may turn on sentence (i). I claimed that expressions of intentions can embed in disjunctions where the other disjunct is not an expression of intention. But imperatives are not standardly thought to behave that way. Compare:

(i') \# The deal will fall through, or go to Vancouver tomorrow.

That sentence seems to me infelicitous.

I am not sure what to make of this disanalogy, in part because (in my dialect of English, anyway), several sentences closely related to (i') are felicitous, including:

(i') The deal will fall through, or you're going to Vancouver tomorrow.

That sentence seems to express a conditional command, albeit one not stated using an imperative clause. Compare also:

(i"') Go to Vancouver tomorrow unless the deal will fall through.

That sentence embeds an imperative in an "unless" clause, which are standardly thought to be related to disjunctions. The felicity of those two types of sentences suggests to me that this disanalogy may be a quirk of the imperative mood in English, and that the similarity between the 
embedding behavior of imperatives and that of expressions of intention may nonetheless be dialectically significant.

I draw two lessons from this discussion. The first is a lesson for metaethicists: reflection on the semantics of expressions of intention suggests that it is far from obvious that NI is a good theoretical model for NNJ. Expressions of intention, unlike normative judgments but like imperatives, cannot embed in the antecedents of conditionals. And (while I have not argued for it here), I suspect there are other unasserted contexts in which they cannot embed, perhaps such as in questions. Even if that suspicion is incorrect, the data about conditionals suggests that the semantics for expressions of intention will significantly differ from that of normative sentences, and so expressions of intention are not an especially good model for normative clauses (and perhaps no better a model for normative sentences imperatives).

The second lesson is simply that proponents of NI who seek to adhere to Anscombe's account of this distinction plausibly face a variant of the Frege-Geach problem. Like proponents of NNJ, they are thus on the hook for providing a solution to it. As discussed above, I think it is an open question whether this can be done. But it is a question that proponents of an expressivist version of NI should be interested in answering.

\section{The Pragmatic Approach}

While many philosophers find Anscombe's characterization of the distinction between expressions of intention and personal predictions compelling, I argue in this section that philosophers willing to part ways with Anscombe (to a certain extent) can adopt an appealing pragmatic account of the distinction. I begin by developing one version of the Pragmatic Approach 
in some detail, before arguing that avoids Frege-Geach problem, is compatible with NI, and has three other features that will make it highly attractive to proponents of NI.

\subsection{Developing the Pragmatic Approach}

The Pragmatic Approach holds that the distinction between the two types of readings of sentences like (d) is explained at the level of pragmatics, not semantics. All sentences like (d) are the same, semantically: their semantic values are their obvious truth-conditions regardless of whether they are expressions of intention or personal predictions. Instead, sentences such as (d) are said to be expressions of intention when they are accompanied by an appropriate conversational implicature, such as an implicature that the speaker now intends to perform the action they mention. ${ }^{46}$ They count as personal predictions when they do not have such implicatures.

How might the idea that uses of sentences like (d) have the appropriate conversational implicature be made plausible? Doing so would require explaining why listeners will, in some contexts, be rational to infer from an "I will..." sentence that the speaker now intends to do the thing they say they will do. Importantly, the Pragmatic Approach must explain the rationality of these inferences in a way consistent with NI-that is, without assuming that intention involves or implies belief. That's because the role of the Pragmatic Approach in the present dialectic is to be an account of expressions of intention compatible with NI. Giving such an explanation is a challenge, because both expressions of intention and personal predictions are assertions, and it is standardly thought that assertions normally carry with them the conversational implicature that the speaker believes the content of the assertion is true, but not that the speaker has any particular

\footnotetext{
${ }^{46}$ As in (Grice 1975).
} 
motivational states. ${ }^{47}$ Since proponents of NI deny that intentions are beliefs, the Pragmatic Approach must thus explain why such assertions sometimes also implicate that the speaker has a certain intention.

I suspect that this challenge can be met in several different ways, each generating a different version of the Pragmatic Approach. And I suspect that different inferential paths may be warranted in different cases of expressions of intention. But here I will develop the Pragmatic Approach by developing just one way this challenge might be met, i.e., by explaining a Gricean inferential path that I suggest might be rational in a wide range of cases.

My proposal exploits three propositions that (I claim) are common knowledge in many circumstances. I argue that these propositions are often common knowledge (or, at least, part of the conversational common ground ${ }^{48}$ ), and that, when they are, they allow listeners to make implicatures characteristic of expressions of intention, by relying on standard Gricean reasoning.

The three pieces of common knowledge my explanation relies on are the following. First, in many contexts it is common knowledge that certain verbs typically denote intentional actions in certain contexts, and other verbs typically denote non-intentional behaviors. I take it that this is uncontroversial: it is simply the idea that in many contexts, many listeners understand that some verbs are verbs of action and others are not. Of course, there may be individual variation in these beliefs, and which verbs are considered to be action verbs may differ from context to context.

Second, in many contexts it is common knowledge that certain intentional actions are normally planned (intended) in advance. In many contexts, many speakers have a shared sense of what kinds of actions are typically spontaneous (e.g., winking), and what kinds of actions are typically planned in advance (e.g., flying to Vancouver). This knowledge need not be exhaustive;

\footnotetext{
${ }^{47}$ As emphasized by (Marušić and Schwenkler 2018). Compare also, e.g., (MacFarlane 2011)

48 (Stalnaker 1973), among others.
} 
the key idea is that there is a reasonable range of common ground about what people typically plan and what people typically do spontaneously. Here, too, there may be variation from context to context and from person to person.

Finally, in many contexts it is common knowledge that people usually believe themselves to be effective agents. This idea has two parts: first, we normally believe that we will do the things we intend to do. While everyone fails sometimes, in many contexts it is common knowledge that most of us succeed in accomplishing our intentions most of the time. Notably, this idea is a standard part of many prominent versions of NI, which offer inferential explanations of why most planning agents normally believe that they will do what they intend to do. ${ }^{49}$ Second, normally, if we now believe we will do something intentionally in the future, we also now intend to do it. That is, we do not normally predict that we will act in ways that we do not (now) intend to act. Of course, we sometimes do just that-we sometimes predict that we will spontaneously do something, or that we will give in to temptation, or be akratic. But (in many contexts) it is common knowledge that those cases are the exception rather than the rule.

Appeal to this trio of propositions provides an appealing account of paradigm examples of expressions of intention and personal predictions. Consider a context in which those three propositions are common knowledge. Given that common knowledge, it is straightforward to see that ordinary Gricean reasoning allows speakers to infer the existence of an intention in paradigm cases of expressions of intention, but not in paradigm personal predictions. Consider first Anscombe's example of "I am going for a walk." Given this common knowledge, it would violate one of Grice's maxims of quantity for someone who did not now have a relevant intention to utter

\footnotetext{
${ }^{49}$ For a Gricean account of why we believe ourselves to be effective agents, see (Paul 2009). For the role of this commitment in Bratman's influential version of NI, see (M. E. Bratman 1989, 450). Note that all versions of NI hold that we do not always believe we will do what we intend to do.
} 
that sentence without further elaboration. ${ }^{50}$ So listeners will be rational to infer that the speaker has such an intention, and the utterance will count as an expression of intention. By contrast, compare Anscombe's paradigm personal prediction, "I am going to be sick." If it common knowledge that this is not something that one does intentionally, utterances of this sentence will (in those contexts) not carry this implicature, for analogous reasons.

The same analysis applies to (d), when it is an expression of intention. If it is common knowledge that going to Vancouver tomorrow is typically planned in advance, it would also violate a maxim of quantity for someone who did not now plan to go to Vancouver tomorrow to assert (d) without qualification. So Gricean reasoning rationalizes forming the belief that the speaker now intends to go to Vancouver tomorrow.

This version of the Pragmatic Approach also offers an appealing account of why, in some cases, utterances of (d)-like sentences can be used only as personal predictions, not as expressions of intention. Specifically, in many contexts where one or more of these three pieces of common knowledge are absent, utterances of (d)-like cannot be (successfully) used as expressions of intention.

To illustrate: consider an agent who says "I will $\phi$," where $\phi$ is replaced by a verb of action, and where the utterance is intended as an expression of an intention to $\phi$. What happens if the three pieces of common knowledge are absent in the context where this is asserted? In each case, Gricean reasoning will not bring the listeners to infer that the speaker has an intention to $\phi .{ }^{51}$ First, suppose that the agent's audience (for whatever reason) does not believe that $\phi$ is a verb of action. Then they won't believe that uttering "I will $\phi$ " without having an intention would violate a maxim of quantity, and so they won't infer that the speaker now intends to $\phi$, and the utterance won't count

\footnotetext{
${ }^{50}$ Compare (Grice 1971, 722).

${ }^{51}$ Unless there is some other Gricean route available, of course.
} 
as having the appropriate implicature. Second, suppose that the agent now intends to do something that is not believed by the audience to be typically planned in advance-perhaps the agent now intends to blink next Tuesday. Since blinking is not (believed to be) planned in advance, an utterance of "I will blink next Tuesday" (without suitable explanation) will not lead to the audience inferring that the speaker now intend to blink next Tuesday. Finally, suppose that the speaker is in a context in which it is not common knowledge that people normally believe themselves to be effective agents. Perhaps the context is a group of sober people who all believe themselves to be liable to relapse into (akratic) alcohol use. In such a context, an utterance of "I will drink this weekend" will not necessarily be interpreted as an expression of intention, since the common knowledge is compatible with that being a prediction of intentional action that is not now intended.

Again, let me emphasize that there may well be other Gricean routes from an utterance such as (d) to a belief that the speaker now has an intention. The Pragmatic Approach holds that such an utterance counts as an expression of intention whenever there is such a route, and so the utterance has an appropriate implicature. I highlight the route above only as a proof of concept that makes plausible the idea that these utterances are often accompanied by such implicatures.

\subsection{Assessing the Pragmatic Approach}

I now turn to the major disadvantage of the Pragmatic Approach, as well as four major advantages.

The major disadvantage is that the Pragmatic Approach requires a departure from Anscombe's characterization of expressions of intention. The Pragmatic Approach, so developed, is compatible with Anscombe's claim that personal predictions and expressions of intention differ in sincerity conditions, but not with her claim that they differ in correctness conditions. Personal 
predictions are insincere when the speaker does not believe the prediction; expressions of intention are insincere when the speaker does not believe they have the intention their utterance implicates that they have. ${ }^{52}$ However, since the Pragmatic Approach holds expressions of intention just are personal predictions with an additional feature, it appears that (on any reasonable interpretation of "correctness conditions") they will share correctness conditions with personal predictions. Philosophers who accept it thus plausibly must give up Anscombe's famous idea that when someone does not do what they expressed an intention to do, "the mistake $[\ldots]$ is one of performance, not of judgment." ${ }^{\text {53 }}$

Some philosophers will see this as a significant strike against the Pragmatic Approach. For those willing to accept it, however, the Pragmatic Approach has four advantages, which may incline many proponents of NI in its favor.

First, as noted above, it avoids commitment to expressivism, and so avoids any version of the Frege-Geach problem.

Second, it provides a natural account of why some sentences are, and some are not, typically used to express intentions. It explains why some paradigm example sentences typically do and some normally do not, express intentions. For example, when it is common knowledge that one rarely does something intentionally (such as be sick), cooperative speakers will not use sentences like "I am going to be sick" to express intentions. A person who now intended to be sick later would violate a maxim of quantity by uttering that sentence without elaboration. The Pragmatic Approach also explains some sentences can easily be used either way: for example, in

\footnotetext{
${ }^{52}$ What about cases in which a speaker does not intend to $\phi$, but falsely believes that they intend to $\phi$, and so expresses an intention to $\phi$ ? Are they sincere or insincere? The criterion above counts them as sincere, but some may wish to hold that, if the false belief is unjustified, the expression of intention is insincere. I thank an anonymous referee for raising this question.

${ }^{53}$ (Anscombe 2000, 4-5).
} 
typical contexts, $(\mathrm{g})$ expresses a conditional intention, but it could be a personal prediction in a context where it was common knowledge that the failure of the deal would precipitate my kidnapping.

The Pragmatic Approach also explains the puzzling features of (j) and (k). I claimed above that there are two different readings of the consequent of $(j)$, but only one natural reading of the antecedent of $(\mathrm{j})$ and $(\mathrm{k})$. The Pragmatic Approach explains this data by considering which inferences a rational agent will make in response to an assertion of these sentences. It is easy to see how, in different contexts, a rational agent might infer from an assertion of (j) either that the speaker has a particular conditional intention, or a particular conditional belief. But, in a range of familiar contexts, assertions of (j) and (k) make rational only one inference about the speaker's attitude toward their antecedent: that the speaker neither believes they will go to Vancouver tomorrow nor intends to do go there. Here's why. In many contexts, a speaker who believes $p$ and unqualifiedly asserts a conditional whose antecedent is $p$ violates a maxim of quantity, by being less than reasonably informative. And (as discussed above) in the very common contexts in which it is common knowledge that speakers believes themselves to be effective agents, and so believe they will do what they intend to do, a speaker who intends that $p$ and unqualifiedly asserts a conditional whose antecedent is $p$ violates a maxim of quantity for the same reason. So, in these familiar contexts, there is only one inference it is rational to make about the speaker's attitude toward the antecedent, and so only one natural reading. ${ }^{54}$

Third, the Pragmatic Approach may seem to be supported by reflection on the cancellation of implicatures. Conversational implicatures can characteristically be cancelled: a sentence that typically implicates some content can be qualified after being uttered, so that it no longer

\footnotetext{
${ }^{54}$ Of course, in the right context, any arbitrary inference can be made by Gricean reasoning.
} 
implicates that content. It is striking that precisely this phenomenon can be observed with apparent expressions of intention. Consider someone who utters (1):

(1) I will go to Vancouver tomorrow. I don't intend to, but the mob always carries out its threats.

Even though the first sentence in (l) is almost always used to express an intention, it can be used as a personal prediction when suitably clarified. According to the Pragmatic Approach, the second sentence is used to cancel the implicature triggered by the first sentence. That expressions of intention have this implicature-like feature is some evidence that they should be understood pragmatically.

Finally, adopting the Pragmatic Approach would allow proponents of NI to rebut a celebrated argument for cognitivism. In a recent article, Marušić and Schwenkler and point out that not only can (d) be used to express an intention, but that it is far more common to for agents who intend to go to Vancouver to utter sentences like (d) than it is to utter sentences like (m): ${ }^{55}$

(m) I intend to go to Vancouver tomorrow.

Marušić and Schwenkler use this this frequency data in an argument for cognitivism about intention. The frequency data entails that we typically express intentions by way of assertions. But we also typically express beliefs by way of assertions. ${ }^{56}$ The best explanation of this coincidence,

55 (Marušić and Schwenkler 2018).

${ }^{56}$ That is, assertions about what we will do, rather than about our attitudes. 
they claim, is that intentions are beliefs. ${ }^{57}$ By contrast, they suggest, NI offers no plausible explanation (or a less plausible explanation) of this coincidence.

The Pragmatic Approach provides NI with a response to this argument. According to the Pragmatic Approach, this frequency data is explained by the fact that contexts in which the relevant Gricean reasoning is rational frequently occur. For example, we often believe ourselves to be effective agents, this is often common knowledge, and we often seek to be cooperative conversational participants. An agent intending to go to Vancouver tomorrow who believes they will succeed would be uncooperatively uninformative to assert (m) instead of (d). Importantly, this explanation of why (d) commonly expresses intentions does not rely on the controversial claim that assertion expresses belief (rather than knowledge). ${ }^{58}$

Indeed, the Pragmatic Approach offers a more plausible account of the relation between (d) and (m) than does the cognitivist account of Marušić and Schwenkler. When will speakers utter (d) rather than (m)? According to the Pragmatic Approach, they will do so when any of the three conditions mentioned above fails to obtain (when we do not believe that we will succeed, when there is no relevant common knowledge, or when we seek to be uncooperative). This is an appealingly straightforward explanation of the data. By contrast, to explain this data, Marušić and Schwenkler must posit that $(\mathrm{m})$ expresses a "partial intention"- - that is, an intention one is not fully settled on, or a conditional intention (to do something only if some uncertain condition obtains). ${ }^{59}$ One thus felicitously utters (m) only when either one is not fully committed to one's action, or one's commitment is conditional on some uncertain condition. But this explanation is highly problematic. It is unclear in their discussion why we use "believe" and "intend" to express

\footnotetext{
${ }^{57}$ (Marušić and Schwenkler 2018, 10). Compare also (Marušić 2015, chap. 3).

${ }^{58}$ Compare, e.g., (Williamson 2010).

${ }^{59}$ (Marušić and Schwenkler 2018, 13-15).
} 
partial versions of those attitudes; it is unclear why we don't use "believe" to express intentions (given that they are beliefs); and it is (in general) implausible that whenever one intends to do something one does not believe one will do, that intention (as a matter of metaphysics) must be partial in the senses they describe. The explanation given by the Pragmatic Approach avoids these problems.

\section{Conclusion}

What do we learn from studying this aspect of the relationship between NNJ and NI? Quite generally, I think we learn that metaethicists should be more interested in intention, and philosophers of action should be more interested in normative judgment, sometimes have been. A theory of mind and action without a theory of intention, a theory of normative judgment, and a theory of the language used to express those states of mind is incomplete.

Does noncognitivism about intention face the Frege-Geach problem? The only conclusion I will argue for definitively is that whether NI faces a variant of the Frege-Geach problem depends on how it treats the distinction between expressions of intention and personal predictions. If that distinction is semantic, then it does face a variant of the problem, albeit one that differs significantly from the one facing NNJ. However, I also argue that there are strong reasons (in addition to the specter of the Frege-Geach problem) for proponents of NI to treat the distinction as pragmatic rather than semantic, if they are willing to depart from certain Anscombean ideas about that distinction. My own sympathies probably lie with the Pragmatic Approach. 


\section{Acknowledgments}

For helpful discussion and comments, I thank Avery Archer, Michael Bratman, I-Sen Chen, Eugene Chislenko, Carlos Núñez, RJ Leland, David Taylor, Peter Hawke, Peter Hanks, Katy Meadows, Huw Duffy, Valerie Tiberius, Paul Tulipana, Jack Woods, Al Mele, numerous anonymous referees for several journals, the participants in a seminar on intention and normative judgment at Stanford, and audiences at the Berkeley-Stanford-Davis Graduate Conference, the Pacific APA, and the University of Minnesota. 


\section{References}

Anscombe, G.E.M. 2000. Intention. 2nd ed. Cambridge, MA: Harvard University Press.

Audi, Robert. 1973. "Intending.” The Journal of Philosophy 70 (13): 387-403.

Baker, Derek. 2010. “Ambivalent Desires and the Problem with Reduction.” Philosophical Studies 150 (1): 37-47. http://www.jstor.org/stable/40783323.

Baker, Derek, and Jack Woods. 2015. "How Expressivists Can and Should Explain Inconsistency.” Ethics 125 (2): 391-424.

Beddor, Bob. 2020. "Fallibility for Expressivists." Australasian Journal of Philosophy 8402. https://doi.org/10.1080/00048402.2019.1699586.

Blackburn, Simon. 1993. Essays in Quasi-Realism. Oxford: Oxford University Press. 1998. Ruling Passions: A Theory of Practical Reasoning. Oxford: Oxford University Press.

Bratman, Michael E. 1987. Intention, Plans, and Practical Reasonx. Cambridge, MA: Harvard University Press.

_. 1989. "Intention and Personal Policies.” Philosophical Perspectives 3: 443-69.

_. 1993. "Shared Intention.” Ethics 104 (1): 97-113.

- 1999. "Davidson's Theory of Intention." In Faces of Intention, edited by Michael Bratman. Cambridge: Cambridge University Press.

Broome, John. 2013. Rationality through Reasoning. Oxford: Wiley-Blackwell.

Castañeda, Hector-Neri. 1975. Thinking and Doing: The Philosophical Foundations of Institutions. Dordrecht: Reidel.

Charlow, Nate. 2014. "The Problem with the Frege-Geach Problem.” Philosophical Studies 167 (3): 635-65. https://doi.org/10.1007/s11098-013-0119-5.

Chicago Manual of Style. 2010. 16th ed. Chicago: University of Chicago Press. . Chicago Manual of Style. 2017. 17th ed. Chicago: University of Chicago Press.

Chislenko, Eugene. 2016. “A Solution for Buridan’s Ass.” Ethics 126 (2): 283-310.

Davis, Wayne A. 1984. “A Causal Theory of Intending.” American Philosophical Quarterly 21 (1): 43-54. https://doi.org/10.5840/jpr_1990_6.

Dreier, James. 2004. "Meta-Ethics and the Problem of Creeping Minimalism.” Philosophical Perspectives 18.

Ferrero, Luca. 2009. "Conditional Intentions.” Nous 43 (4): 700-741.

- 2016. "Pro-Tempore Disjunctive Intentions." In Time and the Philosophy of Action, edited by Roman Altshuler and Michael J. Sigrist. New York: Routledge.

Geach, P.T. 1960. “Ascriptivism.” The Philosophical Review 69 (2): 221-25. 
. 1965. “Assertion.” The Philosophical Review 74 (4): 449-65.

Gibbard, Allan. 1990a. Wise Choices, Apt Feelings. Cambridge, MA: Harvard University Press.

-1990b. Wise Choices, Apt Feelings. New York: Oxford University Press.

- 2003. Thinking How to Live. Cambridge, MA: Harvard University Press.

- 2012. Meaning and Normativity. Oxford: Oxford University Press. https://doi.org/10.1093/acprof.

Grice, H. P. 1971. "Intention and Uncertainty." Proceedings of the British Academy LVII. . 1975. "Logic and Conversation." In Syntax And Semantics, Vol. 3: Speech Acts, edited by P. Cole and J. Morgan, 3:26-40. New York: Academic Press.

Harman, Gilbert. 1976. "Practical Reasoning." The Review of Metaphysics 29 (3): 431-63.

Ludwig, Kirk. 2015. “What Are Conditional Intentions?” Methode 4 (6): 30-60.

MacFarlane, John. 2011. "What Is Assertion?” In Assertion, edited by Jessica Brown and Herman Cappelan. Oxford: Oxford University Press.

Marušić, Berislav. 2015. Evidence and Agency: Norms of Belieffor Promising and Resolving. Oxford: Oxford University Press.

Marušić, Berislav, and John Schwenkler. 2018. "Intending Is Believing : A Defense of Strong Cognitivism.” Analytic Philosophy, 1-27. http://www.marcsandersfoundation.org/wpcontent/uploads/Intending-is-Believing-final.pdf.

Mele, Alfred R. 1992. Springs of Action. Oxford: Oxford University Press.

Moran, Richard, and Martin Stone. 2009. "Anscombe on Expression of Intention." In New Essays on the Explanation of Action, edited by Constantine Sandis. New York: Palgrave Macmillan.

“OED Online.” 2018. Oxford University Press.

Paul, Sarah K. 2009. "How We Know What We're Doing." Philosophers' Imprint 9 (1): 1-24.

Ridge, Michael. 1998. “Humean Intentions.” American Philosophical Quarterly 35 (2): 157-78. https://doi.org/10.2307/20009928.

Sarkar, Anoop. 1998. "The Conflict between Future Tense and Modality: The Case of Will in English." Penn Working Papers in Linguistics V.5 No 2, no. 2: 91-117.

Schroeder, Mark. 2008. Being For: Evaluating the Semantic Program of Expressivism. New York: Oxford University Press.

. 2009. Noncognitivism in Ethics. Oxford: Routledge.

Setiya, Kieran. 2007a. “Cognitivism about Instrumental Reason.” Ethics 117 (4): 649-73.

—. 2007b. Reasons without Rationalism. Princeton: Princeton University Press.

Shah, N., and J. David Velleman. 2005. "Doxastic Deliberation." The Philosophical Review 114 (4): 497-534. https://doi.org/10.1215/00318108-114-4-497. 
Sinhababu, Neil. 2013. "The Desire-Belief Account of Intention Explains Everything." Nous 47 (4): 680-96.

-2017. Humean Nature: How Desire Explains Thought, Action, and Feeling. Oxford: Oxford University Press.

Smith, Michael. 1994. The Moral Problem. Oxford: Blackwell.

Stalnaker, Robert. 1973. "Presuppositions." Journal of Philosophical Logic 2: 447-57.

Stevenson, C.L. 1937. "The Emotive Meaning of Ethical Terms." Mind 46 (181): 14-31.

Thompson, Michael. 2008. Life and Action. Cambridge, MA: Harvard University Press.

Unwin, Nicholas. 2001. "Norms and Negation: A Problem for Gibbard's Logic." The Philosophical Quarterly 51 (202): 60-75. https://doi.org/10.1111/1467-9213.00214.

Velleman, J. David. 1989. Practical Reflection. Princeton: Princeton University Press.

— 2000. "On the Aim of Belief." In The Possibility of Practical Reason. Oxford: Oxford University Press.

Williamson, Timothy. 2010. "Knowing and Asserting.” The Philosophical Review 105 (4): 489523.

Woods, Jack. 2017. “The Frege-Geach Problem.” In Routledge Handbook of Metaethics, edited by Tristram McPherson and David Plunkett. New York: Routledge. 